\title{
Preliminary in vitro analysis of mechanism of cardiac microvascular endothelial barrier function
}

\author{
W. Dong ${ }^{1 *}$, G.N. Zhang ${ }^{2 *}$ and S.H. Gao ${ }^{3}$ \\ ${ }^{1}$ Intensive Care Unit, Jining No. 1 People's Hospital, Jining, \\ Shandong Province, China \\ 2Department of Endocrinology, Jining No. 1 People's Hospital, \\ Jining, Shandong Province, China \\ ${ }^{3}$ Department of Nursing, Jining No. 1 People's Hospital, Jining, \\ Shandong Province, China \\ *These authors contributed equally to this study. \\ Corresponding author: S.H. Gao \\ E-mail: gaoshuhongdn@163.com
}

Genet. Mol. Res. 15 (4): gmr15048864

Received June 8, 2016

Accepted August 30, 2016

Published October 17, 2016

DOI http://dx.doi.org/10.4238/gmr15048864

Copyright (C) 2016 The Authors. This is an open-access article distributed under the terms of the Creative Commons Attribution ShareAlike (CC BY-SA) 4.0 License.

\begin{abstract}
To preliminarily clarify the mechanism of cardiac microvascular endothelial barrier function leading to heart failure, primary HMVEC-D cells were selected and cultured for amplification. The cells were infected with adenovirus vector containing the ADPribosylation factor 6 (Arf6) Q67L gene. Full-length and functional fragments of myeloid differentiation primary response 88 and ARF nucleotide-binding site opener genes were established and transfected into HEK293T cells. GTP-Arf6 pull-down experiment, fluorescent quantitative real-time PCR, immuno-coprecipitation, and transendothelial electrical resistance analysis were conducted.
\end{abstract}


Interleukin-1 $\beta$ (IL-1 $\beta$ ) induced increase in vascular permeability, whereas inhibitor SC514 blocked IL-1 $\beta$-induced transfer of nuclear factor- $\kappa \mathrm{B}$ into the nucleus, from the cytoplasm. Increase in amount of activated Arf6 promoted reduction in transendothelial electrical resistance. In addition, SecinH3 significantly inhibited increase in vascular permeability, and the progression of heart failure was significantly relieved. Cardiac microvascular endothelial barrier function can lead to heart failure. However, IL-1 $\beta$ induced increase in vascular permeability, which nullified the function of cardiac microvascular endothelial barrier. These findings are closely related to the activation of the Arf6-VE-cadherin signaling pathway.

Key words: Heart failure; Endothelial barrier function; IL-1 $\beta$; SC514; Arf

\section{INTRODUCTION}

During heart failure, which is the final stage of various cardiovascular diseases, various types of abnormal microvascular structures can be observed, which may be associated with different cardiac microvascular characteristics (Moreira et al., 2014; Noyes et al., 2014). Endothelial cells (ECs) function as a semipermeable barrier between blood and interstitial tissues, thereby having antithrombotic and regulatory effects on endocrine function and angiostasis. EC injury can cause endothelial dysfunction, which is closely associated with the onset and progression of heart failure (Conrad and Davison, 2014; Masterson et al., 2015). EC damage can be caused by many factors such as cytokines, reactive oxygen species, and lipase. EC injury due to oxygen stress is an important cause of endothelial dysfunction (Dixon et al., 2013; Jacob et al., 2013).

ECs that form the microvascular walls, and the components between them, control the cell composition of blood and the effusion of macromolecular material through blood vessel walls, referred to as microvascular endothelial barrier. In a healthy body, endothelial barrier function is maintained at the normal level, which helps tissues and organs to absorb sufficient oxygen and nutrients and to expel metabolites (Saavedra, 2012). Under pathological conditions, changes in vascular permeability adversely affect endothelial molecular exchange, causing tissue edema and inflammation as well as cardiovascular diseases.

Vascular endothelial cadherin (VE-cadherin) is a vascular EC-specific cadherin that plays a crucial role in maintaining physiological functions of vascular ECs (Moreira et al., 2014). ADP-ribosylation factor 6 (Arf6) is a small GTP-binding protein belonging to the Ras superfamily. Its activity in cells mainly depends on the GTP and GDP transformations. It is active when bound to GTP but is inactive when bound to GDP (Ocak et al., 2014). Blocking the activation of Arf6 can stabilize the vascular endothelium, whereas activating Arf6 can increase the generation of new blood vessels and vascular endothelial permeability (Masterson et al., 2015). Enhancement of vascular permeability caused by EC barrier dysfunction is an important feature of inflammation and initial angiogenesis (Willer et al., 2012). In this study, we preliminarily discussed the mechanism of cardiac microvascular endothelial barrier leading to heart failure, through cytology tests and stimulation analyses.

Genetics and Molecular Research 15 (4): gmr15048864 


\section{MATERIAL AND METHODS}

\section{Materials and reagents}

HEK293T and HMVEC-D cells were acquired from the National Science and Technology Infrastructure Program (Beijing, China) and were preserved in the Cell Center of our hospital, Jining No. 1 People's Hospital, China. Relevant monoclonal antibodies were purchased from Zhongshan Jinqiao Biotechnology Co., Ltd. (Beijing, China). SABC kit for immunohistochemical analysis and $\mathrm{DAB}$ chromogenic system were obtained from BioFriend (New York, NY, USA).

\section{Experimental methods}

\section{Cell culture and transfection}

HMVEC-D cells were regularly cultured and amplified, and adenovirus vectors were used to infect HMVEC-D cells. Adenovirus vectors with green fluorescent protein gene and blank adenovirus vectors were purchased from ViraQuest Inc. (North Liberty, IA, USA). Conventional siRNA method was used to silence genes in HMVEC-D cells. Full-length and related functional structural domains of myeloid differentiation primary response $88(M y D 88)$ and ARF nucleotide-binding site opener (ARNO) were amplified by PCR from the cDNA library. PCR conditions included $94^{\circ} \mathrm{C}$ for $5 \mathrm{~min}$, followed by 30 cycles of $94^{\circ} \mathrm{C}$ for $15 \mathrm{~s}, 58^{\circ} \mathrm{C}$ for $30 \mathrm{~s}$, and $68^{\circ} \mathrm{C}$ for $3 \mathrm{~min}$. The PCR product was preserved at $4^{\circ} \mathrm{C}$. Following this, plasmid vectors with the PCR product were constructed and transfected into HEK293T cells using transfection reagents (Thermo Fisher, Waltham, MA, USA).

\section{GTP-Arf6 pull-down assay}

HMVEC-D cells were pretreated with SecinH3 for $3 \mathrm{~h}$ or were treated with $10 \mathrm{ng} / \mathrm{mL}$ interleukin-1 $\beta$ (IL-1 $\beta$ ) for $48 \mathrm{~h}$ after second siRNA treatment. Data are reported as means \pm standard error, from at least three independent experiments.

\section{Fluorescent quantitative real-time PCR (qPCR)}

qPCR was performed with RNeasy plus mini kit (Qiagen, Valencia, CA, USA) and TaqMan probe was used. PCR was conducted on a 7900 HT Fast Real-Time PCR system (Applied Biosystems, Thermo Fisher).

\section{Immuno-coprecipitation}

HMVEC-D cells were infected with $1 \times 10^{7}$ plaque forming units $/ \mathrm{mL}$ blank vector or Arno-Myc-His adenovirus vector for $48 \mathrm{~h}$ and were treated with $10 \mathrm{ng} / \mathrm{mL}$ IL-1 $\beta$ for $1 \mathrm{~min}$ or 5 min, respectively. HEK293T cells were transfected with plasmids containing full-length or functional domains of $M y D 88$ or $A R N O$ and were incubated overnight. Fresh growth medium was added to the cells and the experiment was performed after $48 \mathrm{~h}$.

Genetics and Molecular Research 15 (4): gmr15048864 


\section{Analysis of EC resistance}

HMVEC-D cells were transferred to an 8-well electrode array culture plate, pretreated with human fibronectin at a density of 50,000 per well. The cells were then monitored using a cell resistance sensor, until the formation of a stable monolayer. After various treatments, an electric cell-substrate impedance sensing system was used for the test.

\section{Fluorescence-activated cell sorting}

Immunofluorescence staining was used to analyze the location of the cell surface adhesion molecules. Cells were incubated with anti-human E-selectin-FITC, anti-human VCAM1-PE, and anti-human ICAM1-FITC E antibodies, at $4^{\circ} \mathrm{C}$ for $20 \mathrm{~min}$.

\section{Statistical analysis}

SPSS14.00 was used for statistical analysis. Measurement data are reported as means \pm standard deviation. Two-independent sample $t$-test was used for comparison between groups. $\mathrm{P}<0.05$ was considered statistically significant.

\section{RESULTS}

\section{Permeability of IL-1 $\beta$-induced ECs increased}

During the EC resistance experiment, the transendothelial electrical resistances of HMVECs treated with dimethyl sulfoxide and SC514 [inhibitor of nuclear factor- $\mathrm{KB}$ (NF$\kappa B$ ) kinase inhibitor] were similar (Figure $1 \mathrm{~A}$ ) and were significantly decreased by IL-1 $\beta$ treatment. qPCR showed that SC514 hardly affected the localization or distribution of VEcadherin. However, VE-cadherins on the EC membrane were significantly decreased on IL-1 $\beta$ knockdown (Figure 1B).

A

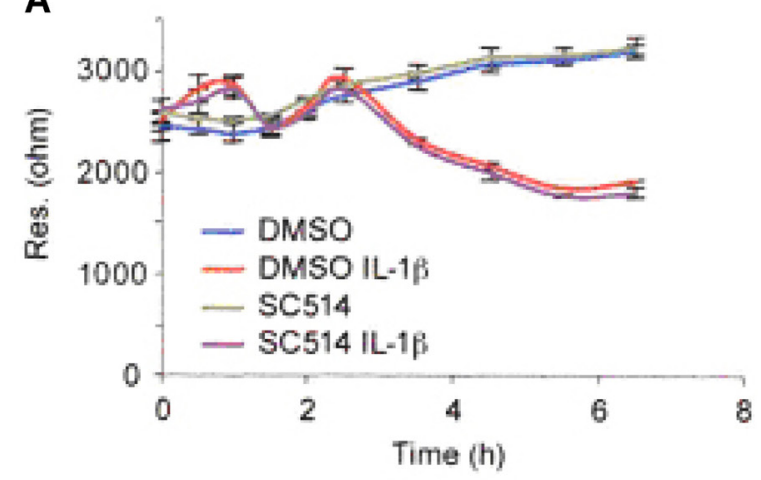

B

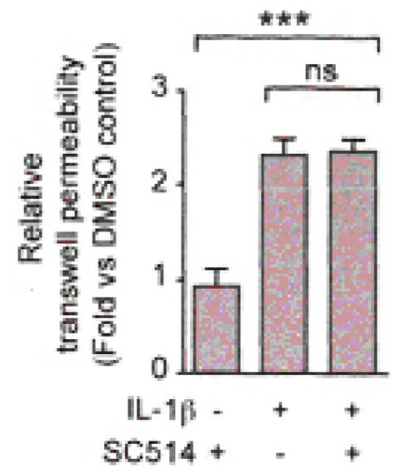

Figure 1. Permeability of IL-1 $\beta$-induced endothelial cells was increased. A. An electric cell-substrate impedance sensing system was used to detect transendothelial electrical resistance of endothelial cell monolayers. B. Transmembrane permeation experiment was used to detect permeability of endothelial cell monolayers. ${ }^{* * *} \mathrm{P}<0.01 ; \mathrm{ns}=$ without significant difference.

Genetics and Molecular Research 15 (4): gmr15048864 


\section{IL-1 $\beta$ activated Arf6 expression, increasing the permeability of ECs}

Arf6 pull-down experiment confirmed that IL-1 $\beta$ stimulation rapidly and persistently activated Arf6 (Figure 2A). EC resistance experiments showed that with increasing titer of Arf6adenovirus vector, the permeability of vascular EC monolayer to horseradish peroxidase was significantly elevated (Figure 2B) and transendothelial electrical resistance was significantly decreased (Figure 2C).

A

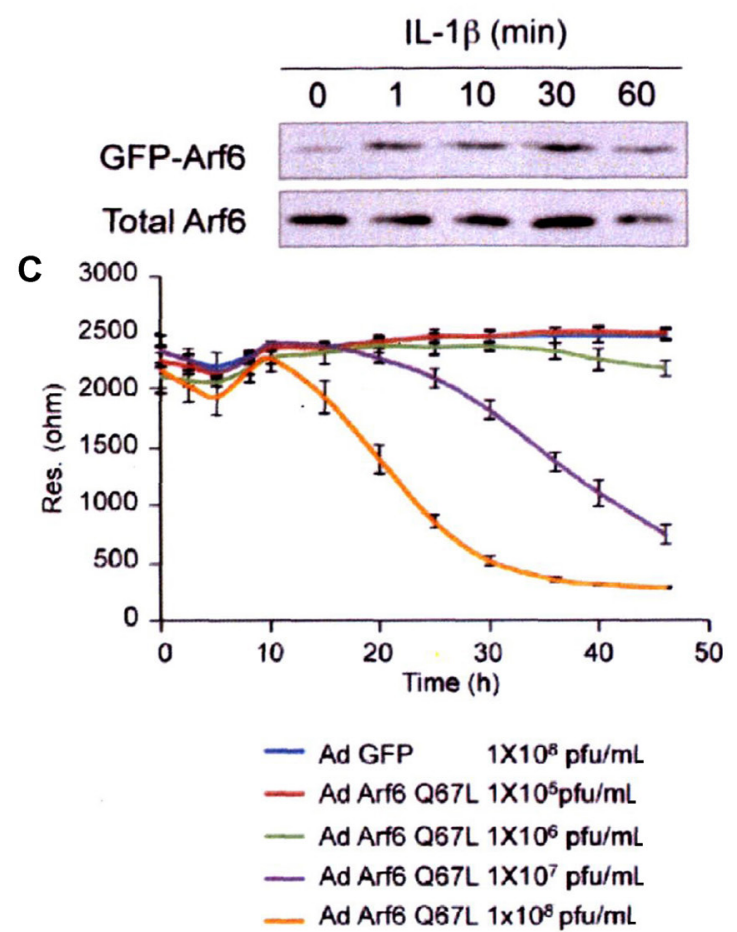

B

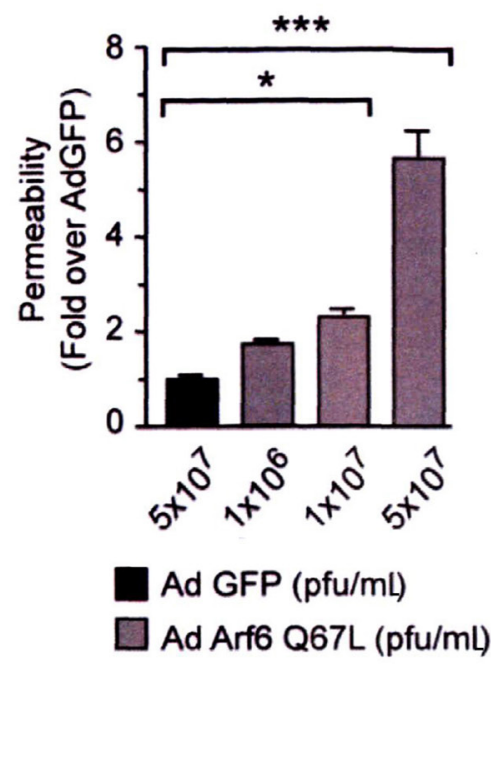

Figure 2. IL-1 $\beta$ was used to activate Arf6 expression, increasing permeability of endothelial cells. A. IL-1 $\beta$ was used to stimulate HMVEC-D cells at different time points. Western blotting was used to detect amount of activated Arf6. B. Transwell permeability test was used to detect permeability of endothelial cell monolayer to horseradish peroxidase. C. An electric cell-substrate impedance sensing system was used to detect transendothelial electrical resistance of endothelial cell monolayers. IL-1 $\beta=$ interleukin-1 $\beta$; Arf6 = ADP-ribosylation factor 6; Res. = resistance. Ad GFP = control; Ad Arf6 Q67L = Arf6-adenovirus vector. The data are reported as means \pm standard deviation. $* \mathrm{P}<0.05, * * * \mathrm{P}<0.01$.

\section{Inhibiting Arf6 reduced vascular permeability of ECs and alleviated heart failure}

Blocking SecinH3, a selective inhibitor of cytohesins that stimulate Arfs, significantly inhibited the heart failure-induced vascular permeability to Evans Blue $(\mathrm{P}<0.01$; Figure $3 \mathrm{~A})$. Application of SecinH3 at the beginning of heart failure also significantly reduced the joint index as compared to the control group (Figure 3B). 

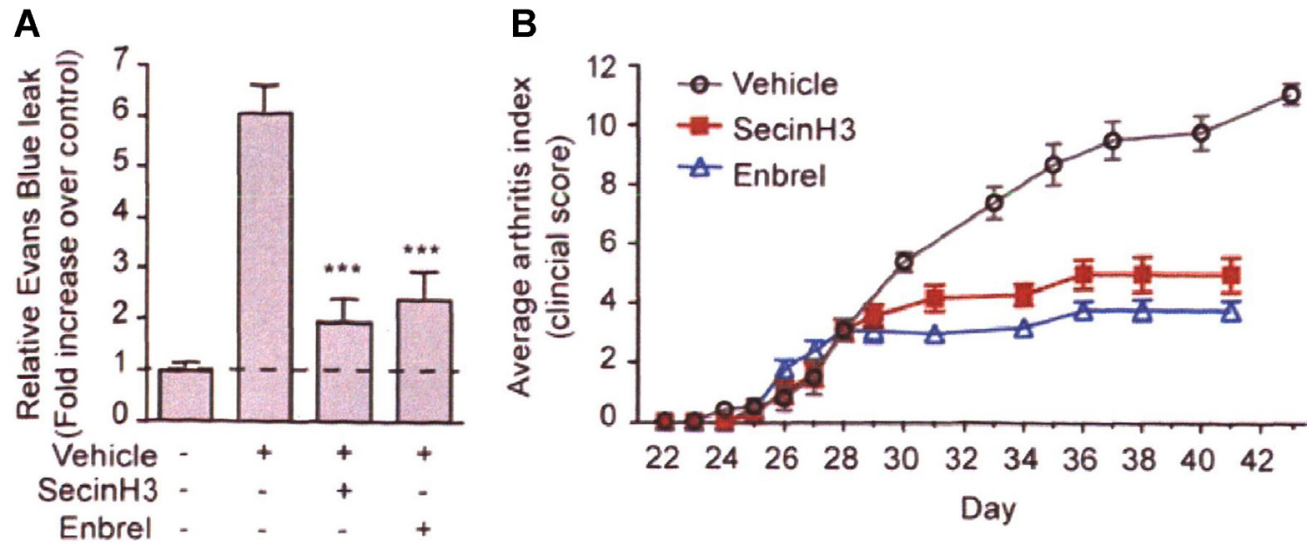

Figure 3. Inhibiting Arf6 reduced vascular permeability and the severity of heart failure. A. Evans Blue test was used to detect vascular permeability. B. The index of heart failure changed in a time-dependent manner. Vehicle: control; SecinH3: treatment with SecinH3; Enbrel: treatment with Enbrel. The data are reported as means \pm standard deviation. $* * * \mathrm{P}<0.01$.

\section{DISCUSSION}

Heart failure is one of the important cardiovascular diseases that threaten the health of middle-aged and old people, with a rising incidence rate in China. Along with the extension of life expectancy, heart failure has attracted attention in China (Dull et al., 2012). Pathogenesis of heart failure had not been clarified hitherto. Various kinds of abnormal microvascular structures can appear during heart failure (Hirase and Node, 2012). Heart is one of the organs that require considerable amounts of nutrients in vivo. Capillaries in the heart are essential nutrition suppliers to the myocardial tissue. Damage to microvascular structure leads to abnormal function of cardiac endothelial barrier, inducing a variety of pathophysiological changes (Murray, 2011).

Vascular endothelium is a barrier structure of the vascular intima and an important endocrine organ. Injury to the vascular endothelium can lead to dysfunction involving multiple viscera and organs, which can lead to onset and progression of heart failure (Xie et al., 2015). Endothelial barrier, composed of ECs joined through interaction of proteins, such as VE-cadherin, controls the liquid infiltrating the adjacent stroma and maintains vascular selective permeability (Lu et al., 2015). Distribution of VE-cadherin in cells can be adjusted by endocytosis, which can remove VE-cadherins from cell surface and can destroy the connection between ECs. At the levels of histology and spatial arrangement, connections between microvascular endothelia and ECs are of great pathophysiological significance to heart failure. Damage to endothelial barrier can lead to myocardial edema, which can aggravate with increasing myocardial interstitial osmotic pressure. In this study, IL-1 $\beta$

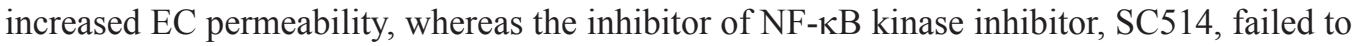
stop the reaction. Studies have shown that after dimethyl sulfoxide treatment, NF- $\mathrm{\kappa B}$ P65 is mainly distributed in the EC cytoplasm. However, after stimulation with IL- $1 \beta, \mathrm{NF}-\kappa \mathrm{B}$ P65 is transferred to the cell nucleus, which can be inhibited by SC514 (Joshi et al., 2015). 
Endothelium plays an important role in controlling leukocyte adhesion and enrollment. Barabutis et al. (2015) found that the number of endothelial cytoplasm membrane vesicles varied in different types of blood capillaries. Microvascular ECs in blood-nerve barrier and blood-brain barrier have different ultrastructures, permeabilities, and properties. Arf6 is mainly involved in the regulation of cytoplasm-membrane transportation and intracellular actin assembly as well as a variety of other physiological functions, including membrane budding, cytokinesis, phagocytosis, vesicle endocytosis, secretion, cell adhesion, and cell migration. In this study, IL-1 $\beta$ activated Arf6 and increased the permeability of vascular ECs. Therefore, we postulated that Arf6 might be an important downstream molecule of IL-1 $\beta$, activated by the increase in vascular permeability induced by IL-1 $\beta$. Arf6 can regulate IL-1 $\beta$ to induce vascular permeability, thereby destabilizing vascular endothelial barrier, by reducing the number of VE-cadherins on cell surface (Cao et al., 2015; Rusu et al., 2015).

Heart failure is an inevitable end of most heart disease patients, which indicates the extent to which cardiovascular diseases can develop. The increase in oxygen free radicals in heart failure patients leads to EC dysfunction, which causes further deterioration of cardiac function, forming a vicious cycle (Horckmans et al., 2015). Vascular ECs also interact with platelets, white blood cells, and blood vessels and can control the growth of blood vessels. We found that the MyD88-ARNO-Arf6 pathway was an effective target for heart failure treatment. The function of Arf6 is determined by its GTP/GDP bound form that is regulated by upstream guanine nucleotide exchange factors and GTPase-activating proteins (Saeed et al., 2014; Coppiello et al., 2015).

In conclusion, cardiac microvascular endothelial barrier function led to heart failure. IL-1 $\beta$ induced an increase in vascular permeability and abrogated the function of cardiac microvascular endothelial barrier, probably through activation of the Arf6-VE-cadherin signaling pathway. However, this study suffered from some limitations associated with in vitro experiments. Many experiments in cellular biology are conducted outside organisms or cells. One of the abiding weaknesses of in vitro experiments is that they fail to replicate the precise cellular conditions of an organism, particularly a microbe. Hence, related in vivo study is ongoing in our group.

\section{Conflicts of interest}

The authors declare no conflict of interest.

\section{ACKNOWLEDGMENTS}

We thank all coauthors for their contribution to this study.

\section{REFERENCES}

Barabutis N, Dimitropoulou C, Birmpas C, Joshi A, et al. (2015). p53 protects against LPS-induced lung endothelial barrier dysfunction. Am. J. Physiol. Lung Cell. Mol. Physiol. 308: L776-L787. http://dx.doi.org/10.1152/ajplung.00334.2014

Cao J, Tsenovoy PL, Thompson EA, Falck JR, et al. (2015). Agonists of epoxyeicosatrienoic acids reduce infarct size and ameliorate cardiac dysfunction via activation of HO-1 and Wnt1 canonical pathway. Prostaglandins Other Lipid Mediat. 116-117: 76-86. http://dx.doi.org/10.1016/j.prostaglandins.2015.01.002

Conrad KP and Davison JM (2014). The renal circulation in normal pregnancy and preeclampsia: is there a place for relaxin? Am. J. Physiol. Renal Physiol. 306: F1121-F1135. http://dx.doi.org/10.1152/ajprenal.00042.2014

Genetics and Molecular Research 15 (4): gmr15048864 
Coppiello G, Collantes M, Sirerol-Piquer MS, Vandenwijngaert S, et al. (2015). Meox2/Tcf15 heterodimers program the heart capillary endothelium for cardiac fatty acid uptake. Circulation 131: 815-826. http://dx.doi.org/10.1161/ CIRCULATIONAHA.114.013721

Dixon DL, Mayne GC, Griggs KM, De Pasquale CG, et al. (2013). Chronic elevation of pulmonary microvascular pressure in chronic heart failure reduces bi-directional pulmonary fluid flux. Eur. J. Heart Fail. 15: 368-375. http://dx.doi. org/10.1093/eurjhf/hfs201

Dull RO, Cluff M, Kingston J, Hill D, et al. (2012). Lung heparan sulfates modulate $\mathrm{K}_{\mathrm{fc}}$ ) during increased vascular pressure: evidence for glycocalyx-mediated mechanotransduction. Am. J. Physiol. Lung Cell. Mol. Physiol. 302: L816-L828. http://dx.doi.org/10.1152/ajplung.00080.2011

Hirase T and Node K (2012). Endothelial dysfunction as a cellular mechanism for vascular failure. Am. J. Physiol. Heart Circ. Physiol. 302: H499-H505. http://dx.doi.org/10.1152/ajpheart.00325.2011

Horckmans M, Esfahani H, Beauloye C, Clouet S, et al. (2015). Loss of mouse P2Y4 nucleotide receptor protects against myocardial infarction through endothelin-1 downregulation. J. Immunol. 194: 1874-1881. http://dx.doi.org/10.4049/ jimmunol.1401364

Jacob M, Saller T, Chappell D, Rehm M, et al. (2013). Physiological levels of A-, B- and C-type natriuretic peptide shed the endothelial glycocalyx and enhance vascular permeability. Basic Res. Cardiol. 108: 347. http://dx.doi. org/10.1007/s00395-013-0347-z

Joshi MS, Williams D, Horlock D, Samarasinghe T, et al. (2015). Role of mitochondrial dysfunction in hyperglycaemiainduced coronary microvascular dysfunction: Protective role of resveratrol. Diab. Vasc. Dis. Res. 12: 208-216. http:// dx.doi.org/10.1177/1479164114565629

Lu Z, Li Y, Jin J, Zhang X, et al. (2015). GPR40/FFA1 and neutral sphingomyelinase are involved in palmitate-boosted inflammatory response of microvascular endothelial cells to LPS. Atherosclerosis 240: 163-173. http://dx.doi. org/10.1016/j.atherosclerosis.2015.03.013

Masterson C, Jerkic M, Curley GF and Laffey JG (2015). Mesenchymal stromal cell therapies: potential and pitfalls for ARDS. Minerva Anestesiol. 81: 179-194.

Moreira RS, Irigoyen M, Sanches TR, Volpini RA, et al. (2014). Apolipoprotein A-I mimetic peptide 4F attenuates kidney injury, heart injury, and endothelial dysfunction in sepsis. Am. J. Physiol. Regul. Integr. Comp. Physiol. 307 : R514-R524. http://dx.doi.org/10.1152/ajpregu.00445.2013

Murray JF (2011). Pulmonary edema: pathophysiology and diagnosis. Int. J. Tuberc. Lung Dis. 15: 155-160, i.

Noyes AM, Dua K, Devadoss R and Chhabra L (2014). Cardiac adipose tissue and its relationship to diabetes mellitus and cardiovascular disease. World J. Diabetes 5: 868-876. http://dx.doi.org/10.4239/wjd.v5.i6.868

Ocak G, Drechsler C, Vossen CY, Vos HL, et al. (2014). Single nucleotide variants in the protein C pathway and mortality in dialysis patients. PLoS One 9: e97251. http://dx.doi.org/10.1371/journal.pone.0097251

Rusu MC, Poalelungi CV, Vrapciu AD, Nicolescu MI, et al. (2015). Endocardial tip cells in the human embryo - facts and hypotheses. PLoS One 10: e0115853. http://dx.doi.org/10.1371/journal.pone.0115853

Saavedra JM (2012). Angiotensin II AT(1) receptor blockers as treatments for inflammatory brain disorders. Clin. Sci. 123: 567-590. http://dx.doi.org/10.1042/CS20120078

Saeed M, Hetts SW, Jablonowski R and Wilson MW (2014). Magnetic resonance imaging and multi-detector computed tomography assessment of extracellular compartment in ischemic and non-ischemic myocardial pathologies. World J. Cardiol. 6: 1192-1208. http://dx.doi.org/10.4330/wjc.v6.i11.1192

Willer EA, Malli R, Bondarenko AI, Zahler S, et al. (2012). The vascular barrier-protecting hawthorn extract WS ${ }^{\circledR} 1442$ raises endothelial calcium levels by inhibition of SERCA and activation of the IP3 pathway. J. Mol. Cell. Cardiol. 53: 567-577. http://dx.doi.org/10.1016/j.yjmcc.2012.07.002

Xie F, Feng L, Cai W, Qiu Y, et al. (2015). Vaccarin promotes endothelial cell proliferation in association with neovascularization in vitro and in vivo. Mol. Med. Rep. 12: 1131-1136.

Genetics and Molecular Research 15 (4): gmr15048864 